\title{
Correction to: Influence of Probiotics Administration Before Liver Resection in Patients with Liver Disease: A Randomized Controlled Trial
}

\author{
Edouard Roussel $^{1,6} \cdot$ Carole Brasse-Lagnel $^{2,3} \cdot$ Jean-Jacques Tuech $^{1,4} \cdot$ Helène Montialoux $^{5}$ • \\ Eloise Papet $^{1} \cdot$ Pauline Tortajada $^{1} \cdot$ Soumeya Bekri $^{2,3} \cdot$ Lilian Schwarz $^{1,4}$
}

Published online: 15 December 2021

(C) The Author(s) under exclusive licence to Société Internationale de Chirurgie 2021

Correction to: World J Surg https://doi.org/10. 1007/s00268-021-06388-7

The authors' names are correct as reflected here. The original article was corrected.

Publisher's Note Springer Nature remains neutral with regard to jurisdictional claims in published maps and institutional affiliations.

The original article can be found online at https://doi.org/10.1007/ s00268-021-06388-7.

Edouard Roussel

edouard.roussel@chu-rouen.fr

1 Department of Digestive Surgery, Rouen University Hospital, 1 rue de Germont, 76031 Rouen Cedex, France

2 Department of Metabolic Biochemistry, Rouen University Hospital, 1 rue de Germont, 76031 Rouen Cedex, France

3 Rouen University Hospital and Normandie Univ, UNIROUEN, Normandy Centre for Genomic and Personalized Medicine, INSERM U1245, 76000 Rouen, France

4 Department of Genomic and Personalized Medicine in Cancer and Neurological Disorders, Normandie University, UNIROUEN, UMR 1245 INSERM, Rouen University Hospital, 76000 Rouen, France

5 Department of Hepatology, Rouen University Hospital, 1 rue de Germont, 76031 Rouen Cedex, France

6 Hôpital Charles-Nicolle (Rouen), 37 Boulevard Gambetta, 76038 Rouen Cedex, France 